\title{
DESENVOLVIMENTO DE CONCEITOS: O PARADIGMA DAS DESCOBERTAS
}

\author{
José Fernando Bitencourt Lomônaco ${ }^{1}$ * \\ Alessandra Gotuzo Seabra Capovilla* \\ Carlos Eduardo Costa \\ Jussara Martins Albernaz ** \\ Marcia Azevedo De Souza \\ Ramatis Monteiro Aguiar
}

\begin{abstract}
Resumo
Keil investigou se a descoberta de essências internas ou princípios causais subjacentes alterariam as categorizações de crianças sobre conceitos de espécies naturais e artefatos. Esse trabalho replica parte do experimento de Keil (1989), buscando validar seus resultados em nosso meio. Participaram 30 crianças, subdivididas em três grupos de 617, 8/9 e 10/11 anos. Foram narradas a cada criança quatro estórias elaboradas por Keil, previamente traduzidas, duas referentes a espécies naturais e duas a artefatos. Eram relatadas situações em que cientistas "descobriam" que, debaixo dos aspectos superficiais de uma coisa, escondiam-se propriedades definidoras de uma outra coisa. Ao final de cada estória, o experimentador perguntava à criança: "Você acha que são X ou Y?", em que X referia-se à aparência do objeto e Y aos atributos definidores. No tocante a artefatos, os sujeitos não se influenciaram pelos aspectos superficiais, avaliando corretamente a identidade dos artefatos. Todavia, em relação às espécies naturais, somente com o aumento da idade os atributos definidores passaram a ser considerados. Tais achados confirmam os de Keil.

Palavras-chave: formação de conceitos; desenvolvimento conceitual; visão teórica.
\end{abstract}

\section{DEVELOPMENT OF CONCEPTS: TRE DISCOVERY P ARADIGM}

\begin{abstract}
Keil aimed at investigating whether the discovery of internal essences, or underlying causal principies, would affeet the way children categorize concepts of natural species and artifacts. The present paper replicates part of Keil' s (1989) experiment. The purpose was to ascertain whether the results were applicable to the Brazilian culture. Thirty children were assigned to three groups of 617, 8/9, and 10/11 years of age. Each was told four stories elaborated by Keil, previously translated, two of them were about natural species and the other two were about artifacts. They depicted situations in which scientists "discovered" that the properties that defined something were hidden under the surface aspects of something else. At the end of each one, the experimenter asked the child whether it was a case of $\mathrm{X}$ (i.e., the appearance of an objeet), or $\mathrm{Y}$ (i.e., the defining attributes of the object). With respect to artifacts, subjects were not misled by surface aspects, but rather were able to correctly assess the identity of the artifacts. However, with regard to natural species, the defining attributes were effective only for the older children. These findings give support to Keil's ones.
\end{abstract}

Key words: concept formation; conceptual development; theory view.

Em trabalho anterior, Lomônaco et alii (1996) fazem uma apresentação das principais teorias psicológicas que, ao longo dos últimos 80 anos, tem procurado explicar o processo de formação de conceitos, quais sejam: as visões clássica, prototípica, dos exemplares e teórica. Assim sendo, no presente estudo vamos considerar muito sucintamente as três primeiras visões e concentrarmo-nos na última delas, uma vez que a pesquisa aqui relatada tem nesta visão seus fundamentos teóricos.

\footnotetext{
${ }^{*}$ Instituto de Psicologia da Universidade de São Paulo; Av. Prof Mello Moraes. 1721; Cx. Postal 66261; CEP 05508-900; Fax: (11) 3813-8895; São Paulo.

E-mail: jfblusp@usp.br

** Centro Pedagógico, UFES
} 
Antes, todavia, é preciso esclarecer o significado que o termo conceito assume neste trabalho. Quando nos referimos a conceito, estamos pensando em um tipo de representação mental. A forma que esta representação assume constitui o núcleo e a especificidade das diferentes teorias de conceitos. Cabe também distinguir entre os termos conceito e categoria, freqüentemente empregados como sinônimos. Neste texto, coerentemente com a tendência atual em diferenciá-los, entende-se por categoria o conjunto de membros representados pelo conceito. Assim, quando falamos do conceito gato, estamos nos referindo a uma representação mental; quando falamos da categoria gato, estamos nos referindo a todos os gatos que já existiram, existem atualmente e existirão no futuro.

A mais antiga, a mais intuitiva e ainda uma das mais influentes teorias sobre a formação de conceitos foi denominada por Smith e Medin (1981) de visão clássica. De acordo com esta concepção, os conceitos são formados pela abstração de atributos comuns a todos os membros de um grupo de coisas, eventos ou pessoas. Assim, por exemplo, diante de figuras que possuam como elementos comuns o fato de serem planas, fechadas, formadas por três lados e três ângulos, ao lado de elementos não partilhados por todos os membros (tais como posição espacial, tamanho, comprimento dos lados etc.), o ser humano abstrai apenas aqueles que são comuns a todos os membros e constrói uma representação mental referente a esse grupo de figuras. Posterior ou concomitantemente a esse processo, costuma-se associar um rótulo verbal a esta representação mental. Neste caso, e em nosso idioma, o rótulo triângulo.

A representação mental do conceito consistiria, pois, numa descrição sumária, resultante de um processo de abstração, que não corresponde exatamente a nenhum dos exemplos, específicos e se aplica a todos os exemplos possíveis. Ao conceber a representação dos conceitos desta maneira, está-se admitindo implicitamente a) que todos os membros da categoria têm a mesma representatividade, ou seja, não faz sentido falar-se em melhores ou piores exemplos de conceitos; b) que os limites das categorias são bem definidos, isto é, não existem casos limítrofes ou duvidosos; e c) que a inclusão de membros numa categoria ocorre de forma absoluta, na base do tudo-ou-nada; ou seja, se um item possui os atributos definidores, ele necessariamente faz parte da categoria; se não os possui, não pertence a ela.

Tais pressupostos da visão clássica foram colocados seriamente em questão, a partir da década de 70, graças principalmente aos trabalhos de Eleanor Rosch (Rosch, 1975, 1978), que viriam dar origem a uma nova maneira de encarar a formação de conceitos: a visão prototípica, também conhecida como visão probabilística. De acordo com essa teoria, os indivíduos, ao entrarem em contacto com os múltiplos e variados exemplos de uma categoria, abstraem deles apenas as características que ocorrem com maior freqüência. E, a partir dessas características abstraídas, formam uma representação sumária da categoria, denominada protótipo. Uma vez formado, o protótipo é utilizado para decidir a inclusão ou exclusão de membros na categoria. Se algum exemplo é suficientemente similar ao protótipo, ele será classificado como membro dessa categoria; se não o for, será rejeitado.

A visão prototípica, pois, a) rejeita os atributos definidores, substituindo-os por atributos característicos; b) admite que os membros de uma categoria não a representam igualmente bem; aqueles que mais se assemelham ao protótipo constituem melhores exemplos do que os menos semelhantes; e c) afirma que os limites das categorias são mal definidos, uma vez que os membros de uma categoria podem, em maior ou menor grau, partilhar características de outras categorias. 
Dessa forma, a visão prototípica parece explicar de maneira satisfatória aspectos questionáveis da visão clássica.

Uma outra maneira de conceber a representação mental dos conceitos é proposta pela visão dos exemplares. Segundo ela os conceitos são representados por um ou alguns exemplos particulares, em vez de por um protótipo único.

Um hipotético exemplo ajudará a entender melhor essa teoria. Suponha-se a situação de um professor que, durante seus anos de magistério, tenha se defrontado com alunos aplicados e alunos desinteressados. A visão dos exemplares pressupõe que, no decorrer de seu trabalho docente, este professor irá gradualmente selecionando exemplos concretos de bons e maus alunos e, posteriormente, usará tais exemplos como uma referência para a inclusão ou exclusão de novos membros dentro de suas categorias de "bons alunos" e "maus alunos".

Embora as visões prototípica e dos exemplares tenham podido explicar, de maneira satisfatória, fenômenos que a visão clássica não consegue dar conta, também essas duas mais recentes concepções têm sido alvo de críticas (ver, por exemplo, Armstrong, Gleitman \& Gleitman, 1983; Murphy \& Medin, 1985). A principal objeção levantada é a de que ambas as teorias, da mesma forma que a visão clássica, baseiam suas explicações do processo de formação de conceitos fundamentalmente na noção de similaridade. Isto é, pessoas, objetos e eventos são agrupados em categorias pelo fato de compartilharem características ou atributos similares. Como salientam Murphy e Medin (1985), usar a similaridade como explicação da formação de conceitos pode levantar mais questões do que fornecer uma resposta. E isto porque a noção de similaridade é demasiadamente ampla.

Um exemplo proposto por esses autores ajuda a entender este tipo de crítica. Se compararmos ameixas e cortadores de grama, poderemos identificar a ocorrência de muitos atributos comuns a ambos os objetos e que, teoricamente, justificariam sua inclusão em uma mesma categoria. Por exemplo, pesam menos do que 250 quilos, são formados por átomos, podem ser vistos a olho nu, ocupam lugar no espaço, podem ser vendidos e comprados, têm nomes, não são transparentes etc. O que esses autores desejam salientar com esta crítica é o fato de que, sem restrições sobre o que deve ou não deve ser considerado como atributos defini dores de um conceito, praticamente qualquer categorização seria possível de ser feita pelo ser humano, o que na verdade não ocorre. Em suas próprias palavras: Esses problemas privam os modelos baseados nas visões probabilísticas e dos exemplares de qualquer real poder explicativo. Sem restrições sobre as características possíveis, por exemplo, os modelos probabilísticos podem explicar virtualmente qualquer resultado (p.166).

Face a tais limitações, vem-se desenvolvendo, a partir da década de 80, uma nova maneira de abordar a formação de conceitos, a visão teórica. De acordo com esta abordagem, nas palavras de seu maior propugnador:...conceitos são construídos como tipos de coisas intrisecamente relacionais. Eles não são entidades isoladas conectadas apenas a serviço de proposições. Nenhum conceito pode ser entendido sem alguma compreensão de como ele se relaciona com outros conceitos... (Keil, 1989; p. 1).

O conceito, portanto, não é mais considerado isoladamente, mas como parte de uma rede de relações com outros conceitos, da qual deriva seu significado. Esta rede de relações é o que comumente consideramos como nosso conhecimento a respeito do mundo, ou nossas "teorias". A palavra teoria aparece entre aspas uma vez que, nesta visão de conceitos, o termo não se refere 
unicamente (nem predominantemente) a teorias científicas, mas (talvez, principalmente) a relações estabeleci das pelo senso comum.

Um exemplo dado por Oliveira (1994) pode ajudar a esclarecer o que se entende por essas relações estabelecidas pelo senso comum. No que diz respeito a animais, as pessoas, mesmo sem qualquer instrução formal, sabem que eles nascem, crescem e morrem; que se alimentam; que produzem filhos da mesma espécie etc. A esse tipo de conhecimento aplica-se o adjetivo "ingênuo". As idéias anteriormente relacionadas constituiriam uma biologia "ingênua". Certamente, também em outras áreas do conhecimento, é possível identificar esta rede de relações entre conceitos, dando origem a uma física "ingênua", a uma psicologia "ingênua" etc. Em resumo, nas palavras de Oliveira (1994), o aspecto fundamental desta visão ... é o de que cada conceito deve ser visto como parte da teoria em que se encontra inserido e de que, na verdade, é elemento constitutivo (p. 37).

Segundo Keil (1989) os conceitos podem ser classificados em três tipos: naturais, nominais e artefatos. As espécies naturais referem-se a classes de coisas que ocorrem no mundo independentemente das atividades humanas e são governadas por um conjunto de leis comuns a todas elas. Como exemplos podemos citar tigre, rosa e cobre. As espécies nominais são conceitos estabelecidos por convenção de uma sociedade na forma de definições simples, nas quais são apresentadas suas propriedades necessárias e suficientes. São as que mais se aproximam, portanto, da visão clássica. Avó, roubo, jantar, triângulo e número primo são alguns poucos exemplos de espécies nominais. Os artefatos constituem um subconjunto das espécies nominais. São objetos produzidos pelo homem e pressupõem a intencionalidade de seu criador, que lhes confere uma função. Alguns exemplos: moeda, chave, agenda, panela e relógio.

Keil acredita que, com o decorrer da idade, ocorre uma mudança qualitativa no desenvolvimento de conceitos. Tal mudança consiste num gradual afastamento das propriedades características dos exemplos de uma categoria, e numa conseqüente aproximação ou atenção a suas propriedades definidoras. Entende-se por propriedades definidoras aqueles atributos ou características que são necessários e suficientes para definir completamente um conceito. Por exemplo, homem tem sido comumente definido como um ser mortal e racional. Entende-se por propriedades características aquele conjunto de atributos que estão comumente associados à maioria dos membros de uma categoria, mas não a todos. Dois exemplos: 1) sol e palmeiras comumente estão associados ao conceito de praia; e 2) cabelos brancos e idade avançada são aspectos característicos do conceito de avó.

Como anteriormente salientado, os conceitos não se desenvolvem isoladamente, mas dentro de uma estrutura relacional com outros conceitos. Tal estrutura relacional constitui um domínio conceitual. Os domínios conceituais são unificados por uma teoria ou conjunto coerente de crenças sobre as relações entre seus conceitos. A mudança qualitativa na representação de um conceito envolve, então, uma reorganização do domínio conceitual.

Em seu programa de pesquisas, Keil (1989) buscou investigar se efetivamente ocorre esta mudança do característico para o definidor e se ela ocorre ao mesmo tempo para todos os domínios, ou se cada domínio segue um curso de desenvolvimento conceitual próprio.

A partir dessas pressuposições, este autor idealiza um conjunto de pesquisas destinado a investigar o desenvolvimento das teorias ingênuas das crianças e suas conseqüências sobre o processo de categorização. Tal conjunto pode ser dividido em três grupos: 1) pesquisas com 
conceitos nominais; 2) pesquisas com conceitos naturais e artefatos, utilizando-se do paradigma das descobertas; e 3) pesquisas com conceitos naturais e artefatos, utilizando-se o paradigma das transformações. Uma réplica de um dos trabalhos com conceitos nominais foi realizado em nosso meio por Lomônaco et alii (1996); uma outra réplica do trabalho de Keil, utilizando-se do paradigma das descobertas, é o objeto do presente trabalho; um terceiro estudo, empregando o paradigma das transformações, está em fase de conclusão.

Através deste segundo conjunto de trabalhos, Keil (1989) procurou investigar se a descoberta de essências internas ou princípios causais subjacentes alteraria as caracterizações das crianças a respeito de espécies naturais e artefatos. O pesquisador formula duas hipóteses referentes aos padrões de desenvolvimento esperados:

a) se as crianças não têm teorias causais bem desenvolvidas a respeito de propriedades que observam nas espécies naturais, elas não darão importância à descoberta de propriedades fundamentais das espécies;

b) crianças que ignoram teorias relevantes podem mostrar padrões de resposta semelhantes, tanto para artefatos quanto para espécies naturais, uma vez que, em nenhum dos casos, elas consideram as propriedades descobertas como importantes.

A fim de avaliar em que medida tais descobertas afetam a categorização, Keil concebeu um procedimento criativo. Foram elaboradas histórias referentes a pares de espécies naturais (p. ex., cavalol/zebra) e de artefatos (p. ex., chave/moeda), nas quais uma entidade tinha todas as características perceptivas e comportamentais de um membro do par, mas propriedades fundamentais ou essenciais do outro. Quatro tipos de propriedades foram selecionadas: 1) propriedades macroscópicas internas, tais como os órgãos e os ossos; 2) propriedades microscópicas internas, tal como a composição do sangue; 3) natureza da descendência; e 4) natureza dos pais. Exemplos destas estórias encontram-se descritas na seção Método/Material.

Neste estudo foram elaboradas dez histórias, sendo cinco referentes a espécies naturais (pêra/maçã; cão/ gato etc.) e cinco a artefatos (prego/chave de fenda, chave/moeda etc.). Três grupos de crianças de 6, 8 e 10 anos, em média, participaram do experimento. As histórias eram contadas aos sujeitos e, após suas respostas, seguia-se uma pequena entrevista destinada a esclarecer dúvidas e conhecer as justificativas apresentadas pelas crianças.

Os resultados demonstraram que, no tocante às espécies naturais, as descobertas dos cientistas não influenciaram a categorização das crianças mais novas, porém afetaram significativamente as das mais velhas. Ou seja, no exemplo da história mencionada, as crianças mais jovens insistiam em considerar esses animais como cavalos, apesar de possuírem sangue e ossos de vaca, serem filhos de vacas e terem bezerros como filhotes. Já as mais velhas afirmaram que os animais eram vacas, apesar de serem muito parecidas com cavalos. Em relação aos artefatos, não houve diferenças significantes entre os grupos de idade: tanto as crianças mais jovens quanto as mais velhas julgaram que o fato descoberto em nada altera a classificação dos diferentes artefatos. Assim, no exemplo considerado, todos os grupos de crianças julgaram que, embora feitos com o metal derretido de moedas, os objetos eram de fato chaves.

Em resumo, os estudos empregando o paradigma das descobertas demonstram evidentes diferenças no desenvolvimento de teorias ingênuas para espécies naturais e artefatos. De acordo com Keil, os resultados referentes a artefatos possibilitam contrastar os padrões de desenvolvimento desses dois tipos de conceitos. Nesses estudos observou-se uma nítida mudança nas respostas, desde 
aquelas que se referem quase exclusivamente a aspectos característicos e negam a importância das propriedades descobertas, até aquelas que levam em conta as descobertas referentes à origem, descendência e partes internas. No dizer de Keil (1989): Os padrões sugerem uma apreciação cada vez maior da importância central dos princípios que organizam as teorias biológicas intuitivas dos adultos (p. 181).

\section{OBJETIVOS}

Uma vez que a visão teórica como explicação do processo de formação de conceitos é uma proposta relativamente nova em Psicologia, pouco divulgada no Brasil, e carecendo ainda de maior número de estudos para validá-la empiricamente, os autores deste trabalho propuseram-se a replicar uma pequena parte dos experimentos de Keil em nosso meio com o objetivo de verificar se, no processo de desenvolvimento de conceitos:

a) ocorre efetivamente uma mudança de ênfase das propriedades características para as propriedades definidoras, com o aumento da idade; e

b) se tal mudança ocorre igualmente para conceitos referentes a espécies naturais e artefatos.

\section{MÉTODO}

\section{Sujeitos}

Participaram como sujeitos 30 crianças, subdivididas em três grupos de dez sujeitos, sendo cinco sujeitos do sexo masculino e cinco do sexo feminino. Os grupos foram assim constituídos: Grupo I: crianças com idade entre 6 anos e 6 anos e 11 meses; Grupo 11: crianças com idade entre 8 anos e 8 anos e 11 meses; e Grupo III: crianças com idade entre 10 anos e 10 anos e 11 meses. Todos os sujeitos eram alunos de escolas municipais ou particulares das cidades de São Paulo e São Bernardo do Campo, situadas em bairros de localização central, com boa infra-estrutura urbana, freqüentadas predominantemente por alunos de classe média.

\section{Material}

Foram utilizadas quatro pequenas estórias traduzidas do estudo de Keil (1989) e adaptadas para o nosso meio, sendo duas referentes a espécies naturais (cavalo/vaca e maçã/pêra) e duas a artefatos (chave de fenda/prego e moeda/chave). Todas as estórias relatavam situações em que cientistas "descobriram" que, debaixo do aspecto superficial de uma coisa, se escondiam propriedades definidoras de uma outra coisa. Por exemplo, sob a aparência externa de um cavalo se escondia um animal cujos órgãos internos eram os de uma vaca. As estórias utilizadas estão a seguir:

\section{Estória 1: cavalo/vaca}

Estes animais vivem numa fazenda, eles relincham, as pessoas colocam selas nas costas deles e andam neles. Estes animais gostam de comer grama e todos chamam eles de cavalo. Mas alguns cientistas foram para esta fazenda estudar esses animais cuidadosamente. Eles fizeram exames de 
sangue, tiraram raios $\mathrm{X}$ e examinaram os animais por dentro com microscópios e descobriram que estes animais não eram como a maioria dos cavalos. Eles eram por dentro iguaizinhos às vacas. Eles tinham sangue de vaca, ossos de vaca, e, quando os cientistas procuraram saber de onde estes animais tinham vindo, descobriram que os pais deles eram vacas e que, quando estes animais tinham filhotes, seus filhotes eram bezerros. O que estes animais realmente são: cavalos ou vacas?

\section{Estória 2: chave de fenda/prego}

Estas coisas servem para manter juntos pedaços de madeira e para pendurar quadros na parede, e todos chamam isto de prego. Mas alguns cientistas foram a uma fábrica onde estas coisas eram feitas para pregar e decidiram estudá-las cuidadosamente. Eles descobriram que elas não eram como a maioria dos pregos. As coisas feitas nesta fábrica eram por dentro como chaves de fenda. $\mathrm{E}$ quando eles olharam para ver como essas coisas eram feitas, eles descobriram que chaves de fenda eram derretidas para fazer pregos. Então, o que você acha que estas coisas realmente são: pregos ou chaves de fenda?

\section{Estória 3: maçã/pêra}

Essas frutas são vermelhas e brilhantes e elas são usadas para fazer tortas e salada de frutas e todo mundo chama essas coisas de maçãs. Mas alguns cientistas foram a um pomar onde algumas dessas árvores crescem e decidiram estudá-las com muito cuidado. Eles olharam com muita atenção dentro delas usando microscópios e descobriram que essas maçãs não eram como as outras maçãs. A parte de dentro delas era como pêras. Elas tinham todas as células de pêras e tudo o mais como elas, e quando eles olharam para descobrir de onde elas vinham eles descobriram que elas nasceram em árvores de pêras. E quando as sementes dessas frutas eram plantadas nasciam árvores de pêras. Então, o que elas são: maçãs ou pêras?

\section{Estória 4: moeda/chave}

Existem coisas que parecem como esta. As pessoas usam essas coisas para abrir portas e também para fechar carros e casas para evitar roubos. Alguns cientistas estudaram em grupo especial dessas coisas que vieram de uma fábrica do Rio de Janeiro, onde elas foram feitas para abrir cadeados. Eles examinaram com muito cuidado usando um microscópio para ver como elas pareciam por dentro e do que elas eram feitas. Eles descobriram que elas não eram como a maioria das chaves. Elas eram feitas exatamente do mesmo material com que as moedas são feitas. Na verdade, quando eles olharam para ver de onde essas coisas vinham, eles descobriram que tinham sido derretidas moedas para fazer essas coisas e, quando elas estavam todas prontas, eles derreteram de novo e fizeram moedas de novo. O que essas coisas são: chaves ou moedas?

Foram empregados, também, gravadores e fitas cassetes para gravar as estórias contadas e as justificativas das crianças.

\section{PROCEDIMENTO}

A cada criança individualmente foram narradas quatro estórias. No início de cada uma delas era mostrado ao sujeito uma figura (desenho ou fotografia) do objeto que estava sendo analisado pelos cientistas (p. ex., um cavalo). Ao final da história, o experimentador perguntava à criança: $\mathrm{O}$ que você acha que são, $\mathrm{X}$ ou $\mathrm{Y}$, em que $\mathrm{X}$ se referia à aparência do objeto e $\mathrm{Y}$ aos atributos 
definidores de um conceito. Após sua resposta, o experimentador fazia uma pequena entrevista com ela, a fim de que a criança justificasse sua escolha.

A ordem de apresentação das histórias foi a mesma para todos os sujeitos. Todas as entrevistas foram gravadas e, posteriormente, transcritas para análise.

\section{RESULTADOS}

As respostas dos sujeitos foram avaliadas independentemente por dois juízes, co-autores do trabalho. Foram atribuídos escores de 1 a 3 às respostas dos sujeitos, obedecendo-se aos seguintes critérios:

a) Escore 1 - quando a criança julga que a identidade não foi alterada pelas descobertas;

b) Escore 2 - quando a criança mostra-se indecisa entre as duas classificações possíveis;

c) Escore 3 - quando a descoberta leva a criança a alterar a classificação.

A concordância interjuizes foi bastante alta para todas as comparações, variando ente 0,90 e 1,0. O grau de concordância (GC) foi calculado através da fórmula

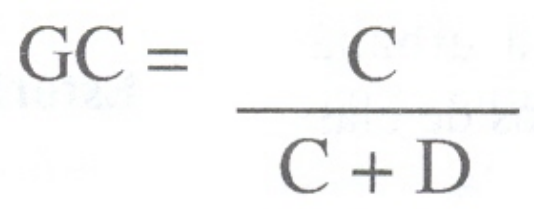

\section{onde}

\section{$\mathrm{C}=$ número de concordâncias \\ $\mathrm{D}=$ número de discordâncias}

As freqüências absolutas e a média dos escores dos sujeitos, por idade, estórias e tipos de conceito, são apresentadas na Tabela 1. 
Tabela 1. Freqüência absoluta e média dos escores dos sujeitos em função da idade, estórias e do tipo de conceito.

\begin{tabular}{|c|c|c|c|c|c|}
\hline \multicolumn{6}{|c|}{ Tipos de Conceitos } \\
\hline \multicolumn{3}{|c|}{ Espécies naturais } & \multicolumn{2}{|c|}{ Artefatos } & \multirow{3}{*}{$\begin{array}{l}\text { Chave I } \\
\text { Moeda }\end{array}$} \\
\hline Idade & Escore & Cavalo / & Maçã / & Prego / & \\
\hline & & Vaca & Pêra & Chave de fenda & \\
\hline \multirow[t]{4}{*}{6 anos } & 1 & 7 & 7 & 2 & 3 \\
\hline & 2 & 0 & 0 & 0 & 0 \\
\hline & 3 & 3 & 3 & 8 & 7 \\
\hline & Média & 1,6 & 1,6 & 2,6 & 2,4 \\
\hline \multirow[t]{4}{*}{8 anos } & 1 & 4 & 5 & 4 & 4 \\
\hline & 2 & 0 & 0 & 1 & 0 \\
\hline & 3 & 6 & 5 & 5 & 6 \\
\hline & Média & 2,2 & 2,0 & 2,1 & 2,2 \\
\hline \multirow[t]{6}{*}{10 anos } & 1 & 1 & 0 & 1 & 5 \\
\hline & 2 & 0 & 1 & 0 & 0 \\
\hline & 3 & 9 & 9 & 9 & 5 \\
\hline & Média & 2,8 & 2,9 & 2,8 & 2,0 \\
\hline & Total & 30 & 30 & 30 & 30 \\
\hline & Média geral & 2,2 & 2,2 & 2,5 & 2,2 \\
\hline
\end{tabular}

Uma inspeção visual da Tabela 1 mostra-nos que, no tocante às espécies naturais, as médias dos sujeitos aumentam de acordo com a idade, variando de 1,6 para o grupo de 6 anos até 2,8/2,9 para crianças de 10 anos. O mesmo não ocorre, todavia, com referência aos artefatos em que não só a amplitude de variação (de 2,0 a 2,8) foi menor que a das espécies naturais, como também não ocorreu consistentemente um aumento das médias dos escores de acordo com a idade.

Foram conduzidas análises estatísticas via Modelo Linear Geral de Análise Multivariada (MANOVA), tendo a variável idade dos sujeitos como fator entre-grupos e a variável tipo de estórias como fator intra-sujeitos. Tais análises revelaram efeitos principais significantes de idade dos sujeitos $\left(\mathrm{F}_{[1,28]} ;=12,9 ; p=0,001\right)$, bem como de tipo de estória $\left(\mathrm{F}_{[1,28]} 5,36 ; p=0,028\right)$. Foi ainda verificado efeito significante de interação entre idade dos sujeitos e tipo de estória $\mathrm{F}_{[1,28]}=4,95 ; p=$ 0,034). Tais efeitos encontram-se representados na Figura 1. Conforme podem ser observados, os escores dos sujeitos nas estórias do tipo "espécies naturais" cresceram monotonicamente com o aumento da idade, porém nas estórias do tipo "artefatos" os escores permaneceram constantes. Análises posteriores de efeito da idade sobre os escores em cada um dos dois tipos de estória separadamente revelaram que o desempenho nas estórias do tipo "espécies naturais" foi afetado significantemente pela idade dos sujeitos $\left(\mathrm{F}_{[1,28]}=13,32 ; p=0,001\right)$, porém aquele nas estórias do 
tipo "artefatos" não foi afetado por tal variável $\left(\mathrm{F}_{[1,28]}=0,085 ; p=0,773\right)$.

De modo a verificar se houve diferenças significantes entre os escores dos sujeitos nas estórias de um mesmo tipo, ou seja, entre os escores nas estórias do tipo espécies naturais e entre os escores nas estórias do tipo artefatos, foram conduzi das análises via Teste t para medidas correlacionadas. Tais análises revelaram que não houve diferença significante entre os escores nas estórias do tipo espécies naturais, porém houve diferença significante entre os escores nas estórias do tipo artefatos $\left(\mathrm{t}_{[28]}=-2,15 ; p=0,04\right)$. Assim, os sujeitos obtiveram escores significantemente superiores na estória prego/chave de fenda quando comparados aos escores na estória chave/moeda.

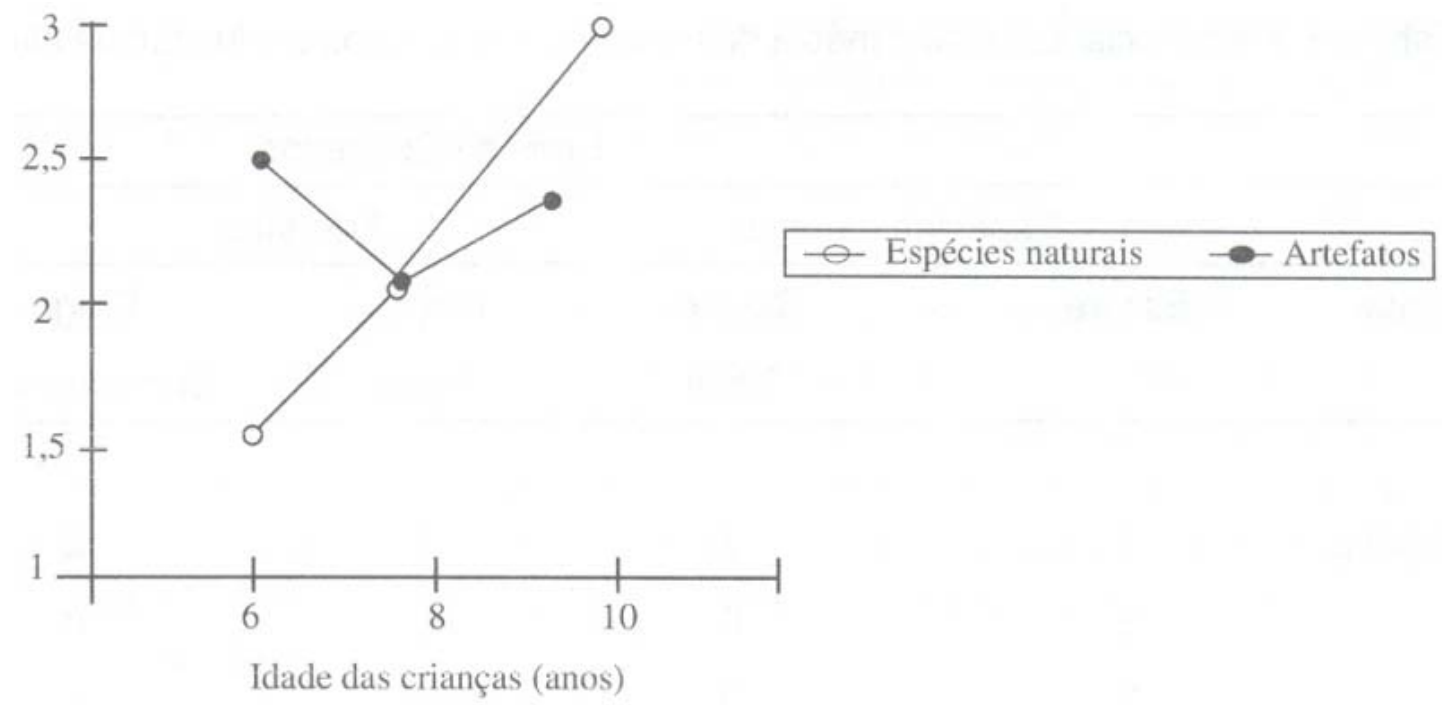

F1. Interação entre idade dos sujeitos e tipo de estória.

\section{DISCUSSÃO}

Os resultados deste estudo são bastante consistentes com aqueles obtidos por Keil (1989). De forma geral, os achados mostraram que, mesmo crianças com idade de seis anos de idade, não se deixam enganar por aspectos circunstanciais e avaliam corretamente a identidade de artefatos. Ou seja, de maneira geral, tais crianças são capazes de distinguir os atributos defini dores dos característicos em se tratando de artefatos. Apesar de ser dito a elas que os objetos considerados resultavam das transformações de outros objetos, as características definidoras, no caso sua função, foram freqüentemente consideradas como o aspecto relevante. Portanto, tais resultados sugerem que, na idade de seis anos, o julgamento das crianças já está bem desenvolvido neste domínio conceitual, uma vez que não foram constatadas diferenças significantes em tais julgamentos com o aumento da idade.

Todavia, quando se trata de espécies naturais, o presente estudo verificou que o julgamento de crianças de seis anos ainda é baseado nos atributos característicos dos conceitos; somente com o aumento da idade é que os atributos definidores passam a ser considerados pelas crianças. Assim, no caso de espécies naturais, crianças menores basearam seus julgamentos de identidade dos animais em função de características superficiais não relevantes. Com o aumento da idade, 
entretanto, tais julgamentos passaram a ser fundamentados em atributos essenciais, no caso em estudo, nos princípios de constituição biológica e reprodução.

Observa-se, portanto, que a mudança de focalização de atributos característicos para os definidores ocorre, em ordem cronológica, primeiramente no domínio de artefatos e, posteriormente, no domínio de espécies naturais. É provável que tal diferença ocorra, visto que os atributos definidores, no caso dos artefatos, são características facilmente observáveis dos objetos (como a sua função), o que poderia facilitar a formação de teorias ingênuas por parte das crianças. Por outro lado, no caso de conceitos de espécies naturais, os atributos definidores são características internas (como constituição celular, formato dos ossos, tipos de órgão) ou menos facilmente constatadas pelas crianças (como princípios de reprodução e de hereditariedade).

A diferença encontrada nas estórias de artefatos (i. e. estória do prego/chave de fenda com escores superiores à estória chave/moeda) provavelmente se deva ao fato de que na estória da chave/moeda havia a seguinte frase: "...eles descobriram que tinham sido derretidas moedas para fazer essas coisas e, quando elas estavam todas prontas, eles derreteram de novo e fizeram moedas de novo". Tal frase pode ter induzido a resposta de que as coisas eram moedas, e não chaves, pois, após as chaves estarem prontas, elas foram derretidas e feitas moedas novamente. O protocolo de respostas de crianças justificavam sua resposta a esta estória dizendo que "se eles derreteram e fizeram moedas de novo, então é moeda".

Em resumo, este estudo, em concordância com o realizado por Keil (1989), sugere que a representação dos conceitos altera-se com o desenvolvimento de teorias ingênuas por parte das crianças, o que as leva a basear seus julgamentos em atributos definidores, desconsiderando os aspectos característicos, não obstante sua saliência perceptiva e mesmo a freqüência com que ocorrem associados aos exemplos do conceito.

Sugere, também, que o desenvolvimento de tais teorias não ocorre ao mesmo tempo para todos os domínios conceituais. Como verificado neste trabalho, as teorias referentes a artefatos desenvolvem-se mais cedo do que as relativas às espécies naturais.

Concluindo, os resultados encontrados parecem ajustar-se bem às previsões da visão teórica como modelo explicativo do processo de desenvolvimento de conceitos. Todavia, somente o acúmulo de evidências empíricas, resultantes de estudos adequadamente planejados, poderá nos dizer se esta é a visão final e definitiva a respeito da formação de conceitos ou apenas mais uma teoria de conceitos, prestes a ser suplantada por outra mais completa e abrangente.

\section{REFERÊNCIAS}

Armstrong, S. L., Gleitman, L. R.; Gleitman, H. (1983). What some concepts might not be. Cognition, 13, 263-308.

Keil, F. K. (1989) Concepts, Kinds, and Cognitive Development. Cambridge, Mass: The MIT Press.

Lomônaco, J. F. B. (1997) A Natureza dos Conceitos: Visões Psicológicas. Tese (Livre-docência). Instituto de Psicologia da Universidade de São Paulo.

Lomônaco, J. F. B, Caon, C. M.; Heuri, A. L. P. V.; Santos, D. M. M.; Franco, G. T. (1996). Do característico ao definidor: um estudo exploratório sobre o desenvolvimento de conceitos. Psicologia: Teoria $e$ Pesquisa, 12(1), 51-60.

Murphy, E. E. \& Medin, D. L. (1986). The role of theories in conceptual coherence. Psychological Review, 
92,289-316.

Oliveira, M. B. (1994). Rumo a uma teoria dialética de conceitos. In: ABRANTES, P. ,org., Epistemologia e cognição. Brasília, Editora da Universidade de Brasília.

Rosch, E. (1975) Cognitive representations of semantic categories. Journal of Experimental Psychology, 104, 192-233.

Rosch, E. (1978) Principles of categorization. Em E. Rosch e B.B. Lyoyd (Ed.), Cognition and Categorization (pp 27-48). Hillsdale, N. J.: Erlbaum.

Smith, E. E. \& Medin, D. L. (1981) Categories and Concepts. Cambridge, MA: Harvard University Press.

Recebido em 30/07/00

Revisado em 29/08/00

Aprovado em 19/09/00 